\title{
Co-crystalization of quercetin and malonic acid using solvent-drop grinding method
}

\author{
Dwi Setyawan*, Rachel Olivia Jovita, Muhammad lqbal, Abhimata \\ Paramanandana, Helmy Yusuf, Maria LAD Lestari \\ Department of Pharmaceutics, Faculty of Pharmacy, Universitas Airlangga, Surabaya 60286, Indonesia
}

*For correspondence: Email: dwisetyawan-90@ff.unair.ac.id; Tel: +6231-5033710; Fax: +6231-5020514

\begin{abstract}
Purpose: To determine the physicochemical properties and in vitro dissolution profile of quercetinmalonic acid co-crystals prepared using solvent-drop grinding method.

Methods: Co-crystallization of quercetin (Q) and malonic acid (MA) in molar ratios of 1:1 (CC1) and 1:2 (CC2) was performed by solvent-drop grinding method with addition of $20 \%(w / v)$ ethanol in a shaker mill run for 30 min. The co-crystal phase was characterized by differential scanning calorimetry (DSC), powder x-ray diffractometry (PXRD), scanning electron microscopy (SEM), and fourier transform infrared (FT-IR) spectroscopy. In vitro dissolution was performed using the paddle method at $100 \mathrm{rpm}$ in the medium of citrate buffer $(\mathrm{pH} 5.0 \pm 0.05)$ containing $2.0 \%$ (w/v) sodium lauryl sulfate at $37 \pm 0.5^{\circ} \mathrm{C}$.

Results: Thermograms from DSC showed that CC1 and CC2 co-crystals had endothermic peaks at 283.02 and $266.61{ }^{\circ} \mathrm{C}$, respectively. These peaks were in-between the melting points of $\mathrm{Ma}$ and $\mathrm{Q}$. The powder diffractogram of CC1 showed new diffraction peaks at 16.21, 19.87, and $28.88^{\circ}$, while CC2 showed new ones at $16.18,19.86$, and $28.83^{\circ}$. There were $\mathrm{OH}$-band shifts in IR spectra from 3411 to $3427 \mathrm{~cm}^{-1}$ for CC1, and from 3411 to $3466 \mathrm{~cm}^{-1}$ for CC2. Images from SEM indicate that the crystal habits and morphologies of the co-crystals differed from those of the original components. The dissolution efficiency of CC2 increased 1.056 times relative to pure $Q$.

Conclusion: Co-crystal phase of $Q$ and MA prepared using solvent-drop grinding (CC1 and CC2) displays physicochemical characteristics different from those of the physical mixtures and their pure components. There is an increase in vitro dissolution as a result of co-crystal formation.
\end{abstract}

Keywords: Co-crystal, Dissolution, Malonic acid, Quercetin, Solvent-drop grinding

\begin{abstract}
This is an Open Access article that uses a funding model which does not charge readers or their institutions for access and distributed under the terms of the Creative Commons Attribution License (http://creativecommons.org/licenses/by/4.0) and the Budapest Open Access Initiative (http://www.budapestopenaccessinitiative.org/read), which permit unrestricted use, distribution, and reproduction in any medium, provided the original work is properly credited.

Tropical Journal of Pharmaceutical Research is indexed by Science Citation Index (SciSearch), Scopus, International Pharmaceutical Abstract, Chemical Abstracts, Embase, Index Copernicus, EBSCO, African Index Medicus, JournalSeek, Journal Citation Reports/Science Edition, Directory of Open Access Journals (DOAJ), African Journal Online, Bioline International, Open-J-Gate and Pharmacy Abstracts
\end{abstract}

\section{INTRODUCTION}

A co-crystal is a crystalline material formed by two or more molecules held together by weak interaction in the same lattice [1]. In the pharmaceutical field, it is formed between an active pharmaceutical ingredient (API) and a co- former without any intrinsic destruction, detachment or covalent bonding. Co-crystal components interact mostly through hydrogen bonding, but other weak bonding such as van der Waals and $\pi-\pi$ interaction may not be ruled out [2]. A suitable co-former for co-crystal formation should possess functional groups that can form 
hydrogen bonds; such groups include carboxylic acids, alcohols, amides, amines, and hydroxyl groups $[3,4]$. Co-crystallization involves numerous techniques in gas, liquid or solid phases. It is important to note that co-crystal phase grows either from the solution in solvent evaporation method or from molecular attachment in grinding method [5].

Grinding method in co-crystallization is divided into two techniques: dry and solvent-drop grinding. Dry grinding (mechanochemistry) is aimed at modifying crystalline phase formation through two mechanisms: molecular diffusion due to displacement, and cleavage planes formation in each cell unit. Solvent-drop grinding is performed by adding a small amount of specific solvent to the grinding process, an amount that can affect the process of co-crystal formation. Solvent-drop grinding possesses several advantages over dry grinding, including shorter time of co-crystal phase formation and possibility of obtaining pure co-crystal [6].

Quercetin ( $Q$ ) is a flavonol which is ubiquitous in fruits and vegetables [7]. It has yellow, needleshaped crystals with a molecular weight of $302.24 \mathrm{~g} / \mathrm{mol}$. Quercetin (Q) has two pKa values of 5.87 and 8.48 , and a melting point of $326{ }^{\circ} \mathrm{C}$ [8-10]. The aqueous solubilities of anhydrous $Q$ and its dihydrate form are 2.15 and $2.63 \mathrm{mg} / \mathrm{L}$, respectively at $25{ }^{\circ} \mathrm{C}[11,12]$. There are five hydroxyl groups in $Q$ which confer strong antioxidant activity on the molecule, in contrast to other polyphenolic compounds [7]. However, Q belongs to class II in Biopharmaceutical Classification System (BCS) due to its low solubility in water and its good permeability [4]. The hydroxyl group in malonic acid (MA) molecular structure enables it to participate in hydrogen bonding two pKa values of MA are 2.83 and 5.70 which is appropriate to form cocrystal with quercetin [13].

This research was conducted in order to improve physicochemical properties and dissolution profile of $Q$ by co-crystal formation. Cocrystallization was performed using solvent-drop grinding, with malonic acid (MA) as co-former.

\section{EXPERIMENTAL}

\section{Materials}

The major reagents used in this study were quercetin monohydrate (Tokyo Chemical Industry Co., Ltd., Japan, Lot: 83N20); malonic acid (E Merck, Germany); sodium lauryl sulfate ( $E$ Merck, Germany), and analytical grade of ethanol (E Merck, Germany).

\section{Observation of co-crystal formation with hot stage microscopy (HSM)}

Co-crystal formation was observed under an Optika B-383PL polarization microscope (Optika, Italy) equipped with an electric heater. A small quantity of $Q$ was placed on an object glass with a cover glass. It was melted by heating and then left to recrystallize. Next, MA was placed on the edge of the glass cover. The sample was then re-heated until it melted completely. As it was melting, MA was slipped under the cover glass to make contact with the $Q$ crystalline surface. The contact zone between $Q$ and MA was observed for the growth of new crystalline phase under a polarization microscope at 100x magnification, and the images were captured using a digital camera.

\section{Production of co-crystals by solvent-drop grinding method}

The components $Q$ and MA were weighed according to the desired molar ratios of $1: 1$ and $1: 2$ (CC1 and $\mathrm{CC} 2$, respectively), and then inserted into the grinding jar, along with $20 \%$ (w/v) ethanol and grinding balls. The grinding jar was placed on the shaker mill and it was run for $30 \mathrm{~min}$.

\section{Preparation of physical mixture}

The components $Q$ and $M a$ were weighed in the molar ratio of $1: 1$ and $1: 2$ (PM1 and PM2 respectively), and then mixed homogeneously in a mortar.

\section{Differential scanning calorimetry (DSC)}

Analysis with DSC was performed to determine any differences in the melting points of $Q, M A$, $P M 1$, and PM2. Each sample (ranging from 5 to $7 \mathrm{mg}$ ) was placed in an aluminium pan and hermetically sealed. The analysis was conducted using DSC 1000 (Linseis, Germany) over the temperature range of $50-350{ }^{\circ} \mathrm{C}$ at a heating rate of $10^{\circ} \mathrm{C} / \mathrm{min}$.

\section{Powder x-ray diffractometry (PXRD)}

Powder x-ray diffraction was performed on $Q$, MA, PM1, PM2, CC1, and CC2 on Phillips X'pert diffractometer (Netherland) with CuKa radiation. Each sample was filled into a glass holder and levelled using a glass plate before placing in the $x$-ray device. The PXRD was performed in $2 \theta$ range of 5 - $40^{\circ}$ at room temperature, at a voltage of $40 \mathrm{kV}$ and current of $40 \mathrm{~mA}$. 


\section{Fourier transform infrared (FT-IR) spectrophotometry}

FT-IR spectroscopy was performed with Jasco 5300 FT-IR spectrophotometer (Jasco, USA) on Q, MA, PM1, PM2, CC1, and CC2. Sample powder was ground homogeneously with potassium bromide ( $\mathrm{KBr}$, spectroscopic grade) in a ratio of $1 \%(\mathrm{w} / \mathrm{w})$ and then pressed to form a disc which was placed in the sample holder and scanned at wavenumber range $4000-400 \mathrm{~cm}^{-1}$.

\section{Scanning electron microscopy (SEM)}

Photographic images of $\mathrm{Q}, \mathrm{MA}, \mathrm{CC} 1$, and $\mathrm{CC} 2$ were captured using TM 3000 Tabletop Microscope (Hitachi, Japan). Each sample was placed on sample holder and coated with gold aluminium of thickness $10 \mathrm{~nm}$. Morphological observation was carried out at appropriate magnification at a voltage of $20 \mathrm{kV}$ and current of $12 \mathrm{~mA}$.

\section{In vitro dissolution studies}

In vitro dissolution studies were carried out on $Q$, PM1, PM2, CC1, and CC2 using Erweka DT 700 (Erweka, Germany) equipped with paddle apparatus. The dissolution medium was citrate buffer ( $\mathrm{pH} 5.0 \pm 0.05)$ with $2.0 \%(\mathrm{w} / \mathrm{v})$ sodium lauryl sulfate (SLS) to achieve sink condition. A sample of $Q(20 \mathrm{mg})$ was added to $900 \mathrm{~mL}$ dissolution medium and stirred at paddle speed of $100 \mathrm{rpm}$ and temperature of $37 \pm 0.5{ }^{\circ} \mathrm{C}$. Then, $5.0 \mathrm{~mL}$ of the sample was collected at 5 , $10,15,30,45$ and $60 \mathrm{~min}$ and filtered through $0.45 \mu \mathrm{m}$ diameter millipore. The absorbance of the filtrate was read at $286 \mathrm{~nm}$ in a UV-Vis spectrophotometer. The concentration $Q$ was calculated from a standard calibration curve. Each sample was analysed in triplicate.

\section{RESULTS}

\section{HSM identification}

The result of co-crystal identification by HSM method are presented in Figure 1. It can be seen that $Q$ showed small columnar shape, while MA showed plate shape characteristics. The contact zone between the two components showed a new crystalline phase in fibrous shape that indicated new crystal (co-crystal) formation.

\section{DSC thermograms}

The thermal behaviours of $\mathrm{Q}, \mathrm{MA}, \mathrm{CC} 1$, and CC2 as characterized by DSC are shown in Figure 2 . It reveals that $Q$ and $M A$ had melting points at 321.92 and $135.07{ }^{\circ} \mathrm{C}$, respectively, and $\mathrm{CC} 1$ thermogram showed endothermic peaks at 95.69, $184.35,283.02$, and $312.70{ }^{\circ} \mathrm{C}$, while CC2 thermogram showed endothermic peaks at 100.02, 125.64, 132.29, 183.97, 266.61, and $302.26^{\circ} \mathrm{C}$. The new endothermic peak at 283.02 and $266.61{ }^{\circ} \mathrm{C}$ for $\mathrm{CC} 1$ and $\mathrm{CC} 2$, respectively indicated the formation of co-crystals.

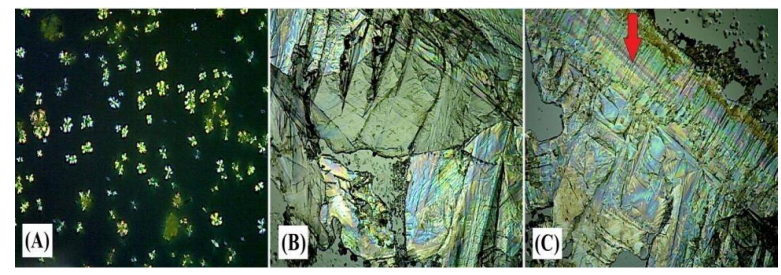

Figure 1: Crystal images obtained from polarization microscope with $x 100$ magnification of $Q(A), M A(B)$, and Q-MA (C) contact zones

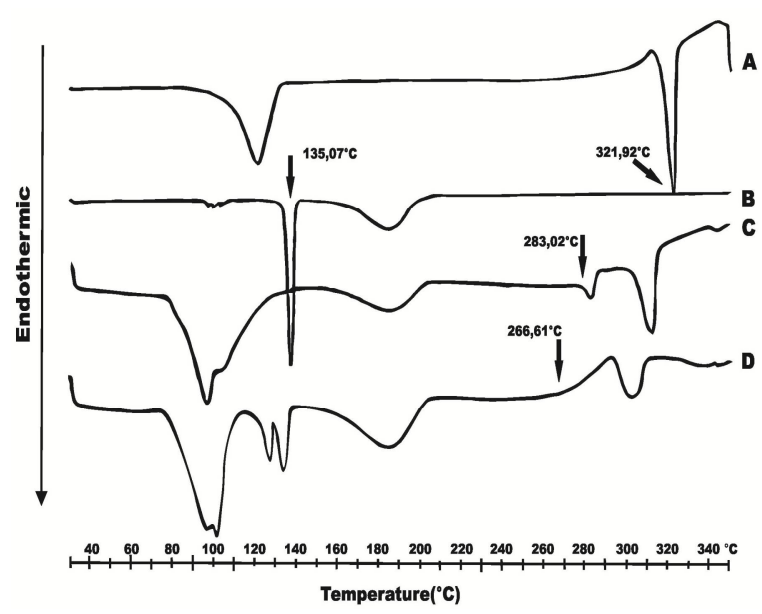

Figure 2: Thermograms of $Q(A), M A(B), C C 1(C)$ and CC2 (D)

\section{Powder diffractograms}

The powder diffraction profiles of $\mathrm{Q}, \mathrm{MA}, \mathrm{PM} 1$, $\mathrm{PM} 2, \mathrm{CC} 1$ and $\mathrm{CC} 2$ are shown in Figure 3. Pure samples of $Q$ and MA showed a number of sharp diffraction peaks at a certain $2 \theta$ degree. However, diffractograms of PM1 and PM2 revealed superimposed pattern from both of components. On the other hand, CC1 and CC2 generated new diffraction peaks at $2 \theta$ (16.21, 19.87, and $28.88^{\circ}$ for CC1; and 16.18, 19.86, $28.83^{\circ}$ for CC2). The new diffraction peaks on both CC1 and CC2 corresponded to formation of new crystalline phases.

\section{FT-IR spectra}

The IR spectra of $Q, M A, P M 1, P M 2, C C 1$, and CC2 are presented in Figure 4. The IR spectra of CC1 and CC2 showed different profiles from those of the pure components, and also from those of the physical mixtures. The $\mathrm{OH}$ - group 
band of $Q$ shifted to higher wave number in cocrystal phase spectra, from 3411 to $3427 \mathrm{~cm}^{-1}$ in CC1, and to $3466 \mathrm{~cm}^{-1}$ in CC2. Furthermore, the peak of $\mathrm{C}=\mathrm{O}$ group in $\mathrm{Q}$ at $1667 \mathrm{~cm}^{-1}$ and 1612 $\mathrm{cm}^{-1}$ disappeared and shifted to $1638 \mathrm{~cm}^{-1}$ in CC2 spectra.

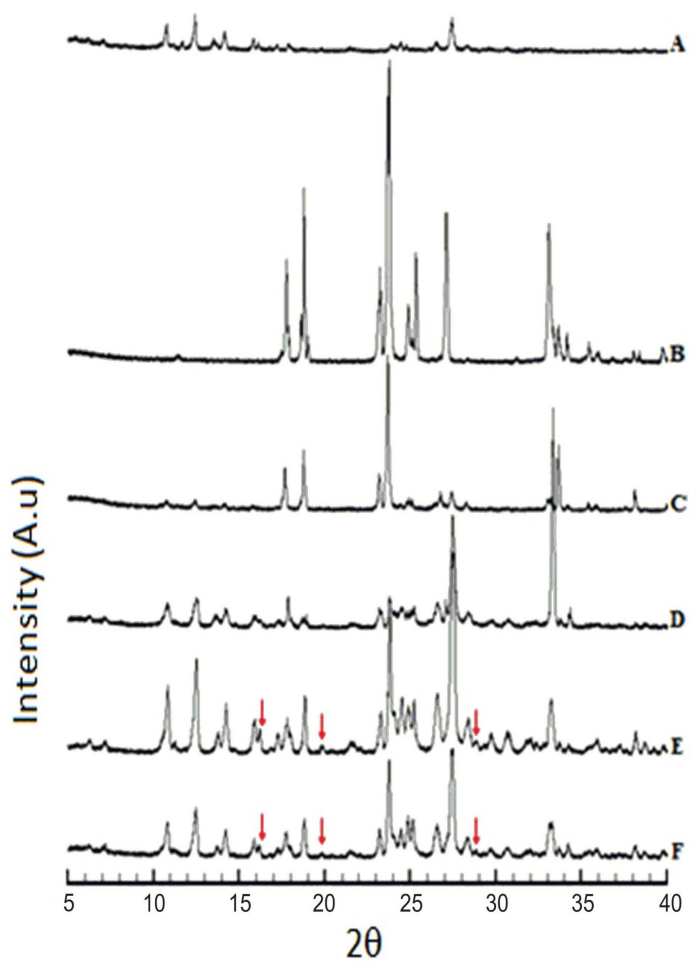

Figure 3: Comparison of $x$-ray diffractogram of $Q(A)$, MA (B), PM1 (C), PM2 (D), CC1 (E), and CC2 (F)

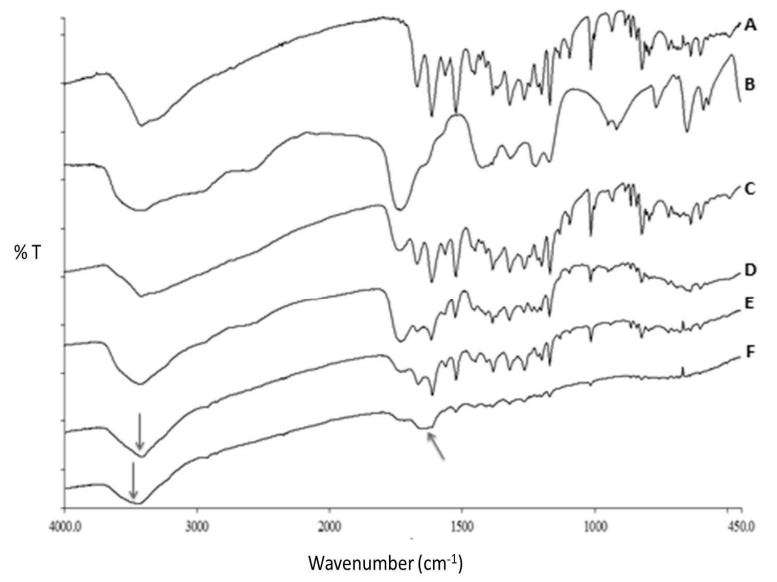

Figure 4: FT-IR spectra of $Q(A), M A(B), P M 1(C)$, PM2 (D), CC1 (E), and CC2 (F). $\downarrow$ indicates band shift in wavenumber

\section{SEM photographs}

Changes in Q-MA co-crystal surface morphology are shown in SEM photographs (Figure 5). At x1500 magnification, $Q$ showed needle-shaped crystal, while MA yielded pebble-shaped crystals at $\times 300$ magnification. The morphologies of CC1 and $\mathrm{CC} 2$ were different from those of the pure components. It was also found that $Q$ lost its habit crystal in $\mathrm{CC} 1$ and $\mathrm{CC} 2$, indicating the formation of new crystalline phase (co-crystal).
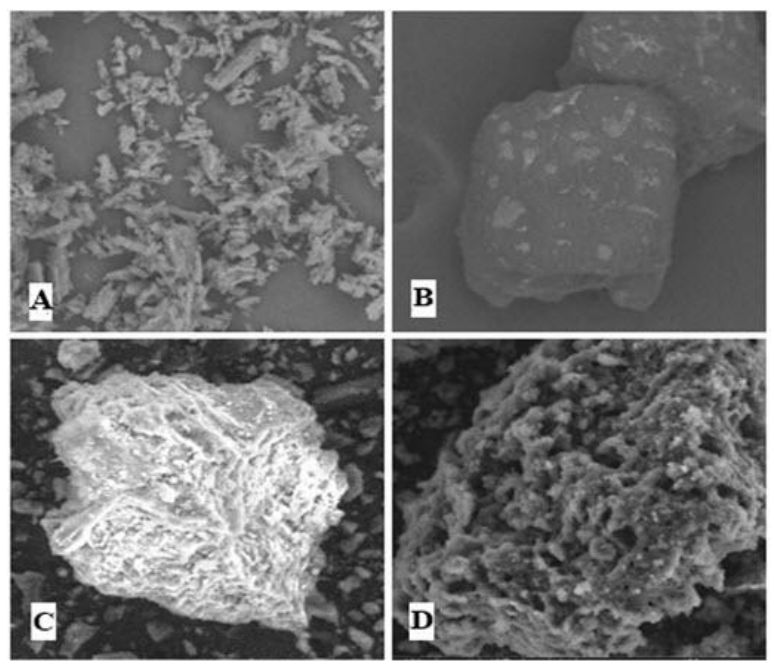

Figure 5: Microphotography of $Q(A), M A(B), C C 1$ (C), and CC2 (D)

\section{In vitro dissolution}

The dissolution profiles of $\mathrm{Q}, \mathrm{PM} 1, \mathrm{PM} 2, \mathrm{CC} 1$, and CC2 are shown in Figure 6. Both co-crystal phases (CC1 and CC2) showed slight improvement in dissolution profile when compared with their physical mixtures (PM1 and $P M 2)$, and pure $Q$.

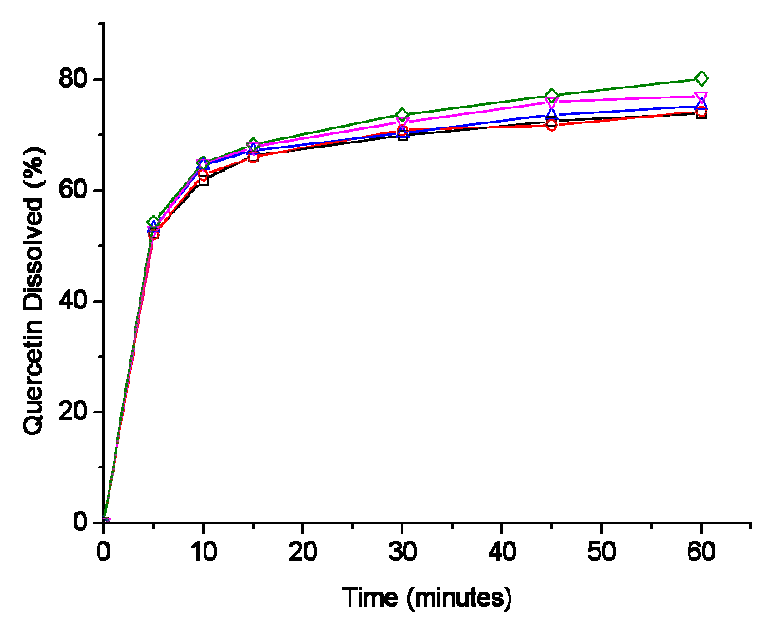

Figure 6: Dissolution rate profiles of $Q(-\square-)$, PM1 (-०), PM2 (- $\left.\Delta^{-}\right), \operatorname{CC} 1(-\nabla-)$, and CC2 $\left(--_{-}\right)$

\section{DISCUSSION}

The HSM method was used as preliminary screening to detect new crystalline phase formation between $Q$ and MA. Recrystallized $Q$ and MA yielded different shape and colours 
when observed under polarization microscope. Variation in colour are influenced by the intensity of light, fragment orientation and the thickness of the beam transmitted by the crystalline phase [14]. The new crystalline phase found in the contact zone is suspected to be a co-crystal phase formed between $Q$ and MA [14].

The phase diagram of $Q$ and $M A$ generated a curve consistent with an incongruent system (unpublished data). In addition, the physical mixture of $Q$ and $M A$ at various composition ratios showed new endothermic peaks in the range of $277.87-282.15{ }^{\circ} \mathrm{C}$, along with endothermic peaks of $Q$ and MA. Endothermic peaks for $20: 80$ and $90: 10$ weight ratios of $Q$ and MA were found in the temperature range of $277.87-282.15^{\circ} \mathrm{C}$. A binary system that forms an incongruent diagram indicates a possible interaction between components in the system [15]. Based on this fact, co-crystal formation of Q-MA with 1:1 and 1:2 molar ratios (CC1 and $\mathrm{CC} 2$ respectively) was carried out. A dehydration event was seen for $Q$ at $\sim 120{ }^{\circ} \mathrm{C}$, and the same event was observed in $\mathrm{CC} 1$ and $\mathrm{CC} 2$ by endothermic peak at 95.69 and $100.02{ }^{\circ} \mathrm{C}$, respectively. A new endothermic peak appeared in-between the melting point of $Q$ and MA. This indicates the formation of co-crystal phase. It is known that a decrease in melting point illustrates interaction between two components in solid state [14].

Co-crystal formation between $Q$ and MA was also established through PXRD analysis. The sharp diffractions observed for $Q$ and $M A$ suggests that both components were in crystalline form [10]. The superimposed patterns of $Q$ and MA in PM1 and PM2 diffractograms indicate absence of interaction between both components, while the new peaks observed in $C C 1$ and $C C 2$ diffractograms suggest that $Q$ and MA interacted under solvent-drop grinding to form co-crystal phase [14].

Hydrogen bonding is the main indicator in cocrystal formation which can be detected through IR spectrum from peak shifts, reduction in peak intensity, and disappearance or appearance of certain peaks [16]. Shifts in $\mathrm{OH}$ - and $\mathrm{C}=\mathrm{O}$ groups of $\mathrm{Q}$ in $\mathrm{CC} 1$ and $\mathrm{CC} 2$ suggest co-crystal formation. Using ChemDraw ${ }^{\circledR}$ Ultra 12.0.2.1076, it was found that hydrogen bonding between $Q$ and MA was more likely to occur between $\mathrm{O}-\mathrm{H}$ in aromatic ring $A$ or aromatic ring $B$ of $Q$ with $\mathrm{O}-\mathrm{H}$ of carboxylic group of MA. This hypothesis was based on the low amount of total energy produced by $M A-Q$ ring $A$ and $M A-Q$ ring $B$ $(99.22 \mathrm{kcal} / \mathrm{mol}$ and $43.85 \mathrm{kcal} / \mathrm{mol}$, respectively).
Dissolution efficiency describes the amount of drug dissolved up to a certain time interval, and the entire dissolution process. It was used to calculate improvement in $\mathrm{Q}$ dissolution in 60 minutes $\left(\mathrm{DE}_{60}\right)$ and the result showed a slight improvement in CC2 dissolution (1.056 times) relative to $\mathrm{Q}$.

The co-crystal phase-induced improvement in solubility is hypothetically caused by new hydrogen bonding between $Q$ and MA molecules [16]. The presence of co-former molecule within the crystal lattice leads to a change in conformational packing or crystal habit which may affect chemical properties of a material, such as solubility and dissolution rate [17]. In addition, the presence of MA hydrogen-bonded to $Q$ will facilitate contact between drug molecules and water, thereby increasing drug solubility [14].

\section{CONCLUSION}

Co-crystal of Q-MA can be formed in 1:1 and 1:2 molar ratio by the solvent-drop grinding method. The co-crystal phases demonstrate increased in vitro dissolution rate compared to $Q$ and the physical mixtures. Due to variations in the physicochemical characteristics of quercetinmalonic acid cocrystal, it can be readily compressed into suitable solid dosage forms.

\section{DECLARATIONS}

\section{Conflict of Interest}

No conflict of interest associated with this work.

\section{Contribution of Authors}

The authors declare that this work was done by the authors named in this article and all liabilities pertaining to claims relating to the content of this article will be borne by them.

\section{REFERENCES}

1. Sanjay A, Manohar D, and Bhanudas S. Pharmaceutical cocrystallization: a review. J Adv Pharm Educ Res. 2014; 4(4): 388-396.

2. Karagianni $A$, Malamatari $M$, and Kachrimanis $K$. Pharmaceutical Cocrystals: New Solid Phase Modification Approaches for the Formulation of APIs. Pharmaceutics. 2018; 10(18): 1-30.

3. Kothur RR. Swetha AS, and Bondili NP. An Outline of Cocrystal Engineering of Pharmaceutical Co-crystals and Applications: A Review. IJPRD. 2012; 4(08): 084092. 
4. Pujari TA. Cocrystals of nutraceuticals: protocatechuic acid and quercetin. USF: Thesis. 2009; 101.

5. Nanjwade VK, Manvi FV, Shamrez Ali M, Basavaraj K, and Maste M. New Trends in the Co-crystallization of Active Pharmaceutical Ingredients. J Appl Pharm Sci. 2011; 01(08): 01-05.

6. Trask $A V$ and $W$. Jones $W$. Crystal engineering of organic cocrystals by the solid-state grinding approach. Top Curr Chem. 2005; 254: 41-70.

7. Materska M. Quercetin and its Derivatives: Chemical Structure and Bioactivity - a Review. Polish J Food Nutr Sci. 2008; 58(4): 407-413.

8. Brewer KJ. The Merck Index: An Encyclopedia of Chemicals, Drugs, and Biologicals, 14th ed. Edited by Maryadele J. O'Neil (Editor), Patricia E. Heckelman (Senior Associate Editor), Cherie B. Koch (Associate Editor), and Kristin J. Roman (Assistant Editor). J Am Chem Soc. 2007; 129(7): 2197-2197.

9. Daniel S, Allen G, and Raj G. Static quenching of ruthenium(II)-polypyridyl complexes by gallic acid and quercetin in aqueous and micellar media. Int Lett Chem Phys Astron. 2014; 13(1): 21-31.

10. Kakran M, Sahoo NG, Li L, and Judeh Z. Fabrication of quercetin nanoparticles by anti-solvent precipitation method for enhanced dissolution. Powder Technol. 2012; 223: 59-64.

11. Srinivas K, King JW, Howard LR, and Monrad JK. Solubility and solution thermodynamic properties of quercetin and quercetin dihydrate in subcritical water. $J$ Food Eng. 2010; 100(2): 208-218.

12. Vasisht $K$, Chadha $K$, Karan $M$, Bhalla $Y$, Jena $A K$, and Chadha R. Enhancing biopharmaceutical parameters of bioflavonoid quercetin by cocrystallization. Cryst Eng Comm. 2016; 18(8): 1403-1415.

13. Strittmatter H, Hildbrand S, and Pollak P. Malonic Acid and Derivatives. Ullmann's Encyclopedia of Industrial Chemistry. Berlin: Wiley-VCH Verlag $\mathrm{GmbH} \& \mathrm{Co}$. KGaA., 2007, [cited 2017 Dec 8]. Available from : https://doi.org/10.1002/14356007.a16_063.pub2.

14. Setyawan $D$, Sari $R$, Yusuf $H$, and Primaharinastiti $R$. Preparation and characterization of artesunate Nicotinamide cocrystal by solvent evaporation and slurry method. Asian J Pharm Clin Res. 2014; 7(1): 62-65.

15. Yamashita $H$, Hirakura $Y$, Yuda $M$, Teramura $T$, and Terada K. Detection of Cocrystal Formation Based on Binary Phase Diagrams Using Thermal Analysis. Pharm Res. 2013; 30(1): 70-80.

16. Veverka M, Dubaj T, Gallovič J, Jorík V, Veverková E, Danihelová $M$, and Šimon P.. Cocrystals of quercetin: synthesis, characterization, and screening of biological activity. Monatsh Chem. 2015; 146(1): 99-109.

17. Bauer J, Spanton S, Henry R, Quick J, Dziki W, Porter W, and Morris J. Ritonavir: An Extraordinary Case of Conformational Polymorphism. Pharm Res. 2001; 18(6): 859-866. 